\title{
Compartimentação geomorfológica da área urbana do município de Senhor do Bonfim - BA enquanto subsídio ao planejamento do uso e ocupação
}

\author{
Geomorphological sharing of the urban area in the municipality of \\ Senhor do Bonfim - BA as a subsidy to planning use and occupation
}

\section{Felipe Souza Reis' ${ }^{10}$, Sirius Oliveira Souza'(i)}

I Universidade Federal do Vale do São Francisco (UNIVASF), Colegiado de Geografia, Senhor do Bonfim, BA, Brasil

\section{RESUMO}

A sociedade está distribuída sobre um ambiente que possui características evolutivas (ACSELRAD, 1992). Nesse quadro, cabe aos componentes sociais dotar de instrumentos que possam analisar a complexidade sistêmica deste ambiente, bem como sua singularidade (LIMBERGER, 2006). Nesse viés, a cartografia geomorfológica constitui-se em um importante instrumento para compreensão do espaço (QUEIROZ, 2012). Dessa forma, este trabalho tem o objetivo de propor uma compartimentação geomorfológica da área urbana do município de Senhor do Bonfim - BA, enquanto subsídio ao planejamento do uso e ocupação da terra. Para isso, utilizou-se enquanto alternativa analítica fotografias áreas em formato digital, em escala 1:70.000, adquiridas gratuitamente da CBPM (2020), bem como dados do Bing Maps Aerial e da Carta Geológica e Topográfica de Senhor do Bonfim, disponibilizada pela SEI (2015). Entre os resultados, os pedimentos constituem-se o compartimento predominante, cobrindo $91,1 \%$ do perímetro urbano, as planícies fluviais apresentaram total de 7,9\%, e por fim os inselbergues com $1 \%$. Este tipo de trabalho se torna importante à medida que o mapeamento geomorfológico proposto oferece tanto à comunidade, quanto as autoridades competentes, escopo considerável na adoção de medidas estruturais de proteção ambiental.

Palavras-chave: Geomorfologia; Planejamento ambiental; SIG

\section{ABSTRACT}

Society is distributed over an environment that has evolutionary characteristics (ACSELRAD, 1992). In this context, it is up to the social components to provide instruments that can analyze the systemic complexity of this environment, as well as its uniqueness (LIMBERGER, 2006). In this perspective, geomorphological cartography is an important instrument for understanding space (QUEIROZ, 2012). Thus, this work aims 
to map the geomorphological compartmentalization of the urban area in the municipality of Senhor do Bonfim - BA, as a subsidy for planning the use and occupation of land. For this, it was used as an analytical alternative area photographs in digital format, on a scale 1:70,000, acquired free of charge from CBPM (2020), as well as data from Bing Maps Aerial and the Geological and Topographical Map of Senhor do Bonfim, made available by SEI (2015). Among the results, petitions constitute the predominant compartment, covering $91.1 \%$ of the urban perimeter, the river plains had a total of $7.9 \%$, and finally the inselbergs with $1 \%$. This type of work becomes important as the mapping of geomorphological compartments offers both the community and the competent authorities a considerable scope in the adoption of structural measures for environmental protection.

Keywords: Geomorphology; Environmental planning; SIG

\section{INTRODUÇÃO}

A sociedade está distribuída sobre um ambiente que possui características evolutivas (ACSELRAD, 1992). Nesse quadro, cabe aos componentes sociais dotar de instrumentos que possam analisar a complexidade sistêmica deste ambiente, bem como sua singularidade (LIMBERGER, 2006).

No cenário de análise destes ambientes naturais, a geomorfologia constituise em grande aliada no diagnóstico da paisagem. Segundo Christofoletti (2001), a Geomorfologia é a ciência que estuda as formas de relevo, sua gênese, composição e os processos correlatos. Casseti (2001) afirma que a Geomorfologia estuda o que há de mais concreto na superfície terrestre, sendo conhecida também como ciência do relevo, evidenciando estrutura e processos, tanto do tempo pretérito, quanto do presente.

Similarmente, a Geomorfologia concebe a possibilidade de conhecimento dos aspectos paisagísticos dos territórios, como os patrimônios geomorfológios, a geobiodiversidade, entre outros. Sendo assim, consolida-se enquanto ramo da ciência geográfica de cunho evolutivo e de abordagem dos processos que atuam no relevo (SMITH; PARON; GRIFFITHS, 2011). E, pela possibilidade de propiciar estudos que versem sobre as interações e características entre ação antrópica e feições geomorfológicas de um determinado recorte espacial, é que se torna possível aliar os aspectos do campo geomorfológico aos métodos de prevenção e 
mitigação de problemas ambientais decorrentes do uso desordenado da terra, através da cartografia geomorfológica (MENDES, 2015).

A cartografia geomorfológica constitui-se em um importante instrumento de compreensão do espaço por meio de mapas temáticos que permitem conhecer a superfície terrestre (QUEIROZ, 2012; CUNHA et al., 2003) é uma área vasta, que oferece uma série de dados e fatos geomorfológicos que permitem representar as formas de relevo (CASSETI, 2005). Logo, configura-se em um método cartográfico que se torna importante ao integrar as diferentes métricas e métodos para observação, desenho e modelagem da superfície terrestre (EISANK, 2011; BIERMAN; MONTGOMERY, 2013)

Tendo em vista a potencialidade da cartografia geomorfológica para análise das alterações naturais do meio físico, associadas às ações antrópicas e sua pungente ocupação das áreas naturais, Saadi (1997), afirma que as intervenções técnicas da cartografia geomorfológica aplicada ao planejamento ambiental têm sido prerrogativa de grande destaque no que diz respeito ao trato das questões de controle e monitoramento, bem como de avaliação e controle de riscos ambientais potenciais (MENDES, 2015; SANTOS, 2020).

Enquanto alternativa ao diagnóstico, é possível mencionar pesquisas de autores como Bocco, Mendoza e Velázquez (2001), que evidenciaram no estado de Michoacan, centro-oeste do México, as principais formas de relevo em níveis de reconhecimento 1:250.000 e semi-detalhados 1:50.000, resultando em um grande inventário sinóptico de recursos naturais. Destacam-se também pesquisas de autores como Smith, Paron e Griffiths (2011), que, em âmbito internacional, realizaram significativas contribuições de mapeamento geomorfológico em ambientes variados, utilizando técnicas 'multiescalares', pautadas na extração e simbologia de dados mapeados em áreas rurais com risco de deslizamento no Nepal.

No contexto brasileiro, Vasconcelos et al., (2008), buscaram diagnosticar a área localizada na Depressão Sertaneja (Pediplano do Baixo São Francisco), por 
meio de uma análise morfodinâmica, expondo zonas de potenciais riscos e grau de instabilidade processual no município de Tacaratu, na microrregião de Itaparica, Pernambuco. Ainda no semiárido nordestino, Lima et al., (2013), indicam limites e potencialidades da cartografia geomorfológica no semiárido baiano, ao terem como área em estudo a bacia hidrográfica do rio Bom Sucesso, no médio curso do rio Itapicuru - BA, os autores evidenciam a predominância de pediplanos formados pela coalescência de pedimentos, associados as elevações residuais dos inselbergues.

Baseado nesses parâmetros e considerando a relevência da temática, é possível legitimar a elaboração deste trabalho, a priori, pela ausência de mapeamentos geomorfológicos na área urbana do município de Senhor do Bonfim - BA. Desta maneira, a escala adotada para esta análise (1:70.000) pode facilitar propostas de mitigação e prevenção de problemas ambientais advindos do uso desordenado da área urbana do município (ADELI e KHORSHIDDOUST, 2011).

Além das características de gestão territorial e assessoramento aos projetos de planejamento ambiental, este trabalho também se justifica com base nos instrumentos da Lei $n^{\circ}$. 6.766/79 (BRASIL, 1979) que indica entre suas diretrizes, a necessidade do diagnóstico e mapeamento dos terrenos urbanos, com destaque para as áreas indicadas a preservação, tais como os terrenos alagadiços e sujeitos a inundações.

Diante de tais constatações, este trabalho tem o objetivo de propor uma compartimentação geomorfológica inédita em escala 1:70.000 para a área urbana do município de Senhor do Bonfim - BA, enquanto subsídio ao planejamento do uso e ocupação da terra. Ressalta-se que a definição da escala do trabalho pautase na disponibilidade de fotografias aéreas para a área em estudo. 


\section{MATERIAIS E MÉTODOS}

\subsection{Caracterização da área}

Ao longo do semiárido brasileiro, optou-se por estudar a área urbana do município de Senhor do Bonfim (Figura 1), que possui 20,429 km² de área dentro do território municipal. Tal escolha justifica-se em razão deste município ser centro regional do Território de Identidade do Piemonte Norte do Itapicuru (BA) e por sediar as principais instituições de ensino superior da região. O município de Senhor do Bonfim está localizado entre os paralelos 10²5'56.37"S e 10³2'36.87"S e os meridianos 40¹1'27.97"O e 40¹4'55.88"O de Greenwich, situado ao centro norte do estado da Bahia, limitando-se ao norte com Jaguarari, Filadélfia e Itiúba ao sul, Campo Formoso e Antônio Gonçalves a oeste e Andorinha a leste e compõe o município pólo do Território de Identidade Piemonte Norte do Itapicuru (SEI, 2018).

Figura 1 - Mapa de localização da área urbana de Senhor do Bonfim - BA.

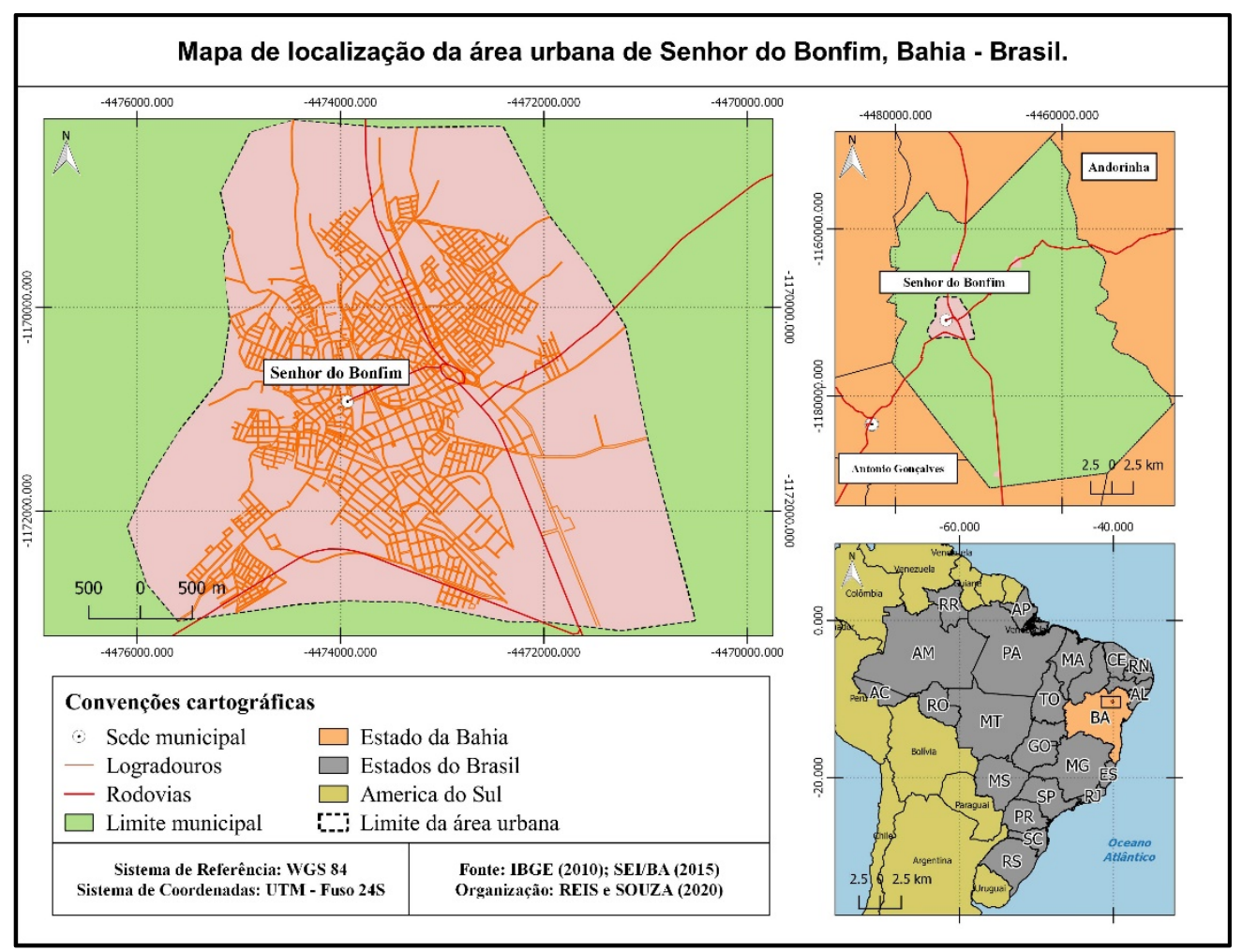

Fonte: Adaptado de IBGE (2010) e SEI (2015) 
O clima da área urbana de Senhor do Bonfim é classificado como do tipo tropical semiárido, que se caracteriza pela escassez e irregularidade das precipitações pluviométricas que não ultrapassam 800mm/ano (IBGE, 2007). Segundo o Instituto Nacional Meteorologia (INMET, 2019), por meio da estação meteorológica Senhor do Bonfim (A428), evidencia-se que as temperaturas médias são elevadas, em torno de $27^{\circ} \mathrm{C}$ e a amplitude térmica média anual é em torno de $5^{\circ} \mathrm{C}$, o que contribui para o desenvolvimento da vegetação Savana Estépica, denominada Caatinga (IBGE, 2012; RADAMBRASIL, 1983).

Referente ao contexto geológico, a área urbana de Senhor do Bonfim estrutura-se sobre o domínio geotectônico da Bahia Oriental, inserido no Cráton do São Francisco, ao qual se associam terrenos do arqueozoico e paleoproterozoico do tipo granito-greenstone e cinturões móveis de médios e altos graus metamórficos (CBPM, 2003). Desta forma, a área em estudo apresenta predominância de paragnaisses e migmatitos, que ao serem expostos aos processos pedogenéticos, contribuem principalmente para a formação de Latossolos Vermelho-Amarelo, Neossolos Litólicos e Neossolos Regolíticos (CBPM, 2003).

Os solos supracitados estão associados aos distintos compartimentos geomorfológicos do município, que apesar de ter como matriz espacial a ocorrência de pedimentos e pediplanos, se diferencia em seu trecho oeste pela existência de feições morfologicamente movimentadas (Serra da Jacobina), associadas ao Grupo Jacobina e demarcadas por diversos fraturamentos e falhamentos, que se tornam trajetos preferenciais para os canais fluviais (RADAMBRASIL, 1983).

Quanto à hidrografia, a bacia no qual a área está inserida é a bacia hidrográfica do Rio Itapicuru (SEI, 2018), representada na área pela presença do riacho do Alambique e do córrego da Malária, ambos com caraterísticas efêmeras. Cabe ressaltar que canais efêmeros, são considerados como canais que 
permanecem secos durante a maior parte do ano, sendo abastecidos em períodos chuvosos seguidos da precipitação (LEOPOLD e MILLER, 1956; LIMA, 2014).

Quanto as características clinográficas da área urbana, estas apresentam maiores picos de declividade ao norte $(<37 \%)$, onde há presença do inselbergue Morro da Viúva. Ademais, predomina-se na área urbana declividades máximas de 15\%, como expõe a Figura 2. Cabe salientar que entender os aspectos da declividade implica na compreensão de ordenamento, haja vista o alto índice de intervenção antrópica em áreas naturais. São exemplos desta modificação os aterros, construções vicinais e desmatamento de vertentes (JATOBÁ, 1994).

Figura 2 - Mapa da declividade da área urbana de Senhor do Bonfim - BA.

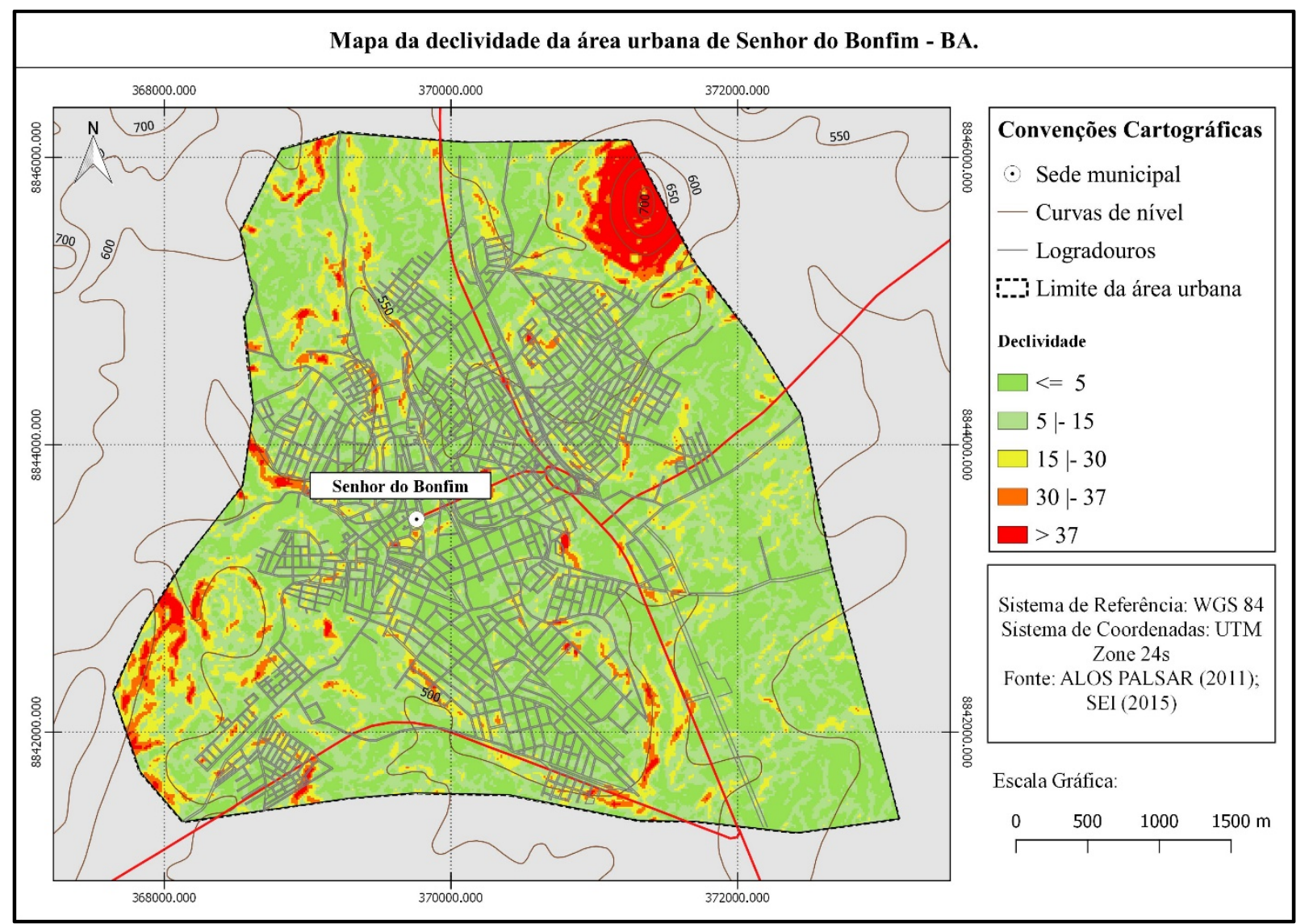

Fonte: Autores (2020)

No que se refere à vegetação, pode-se afirmar sua concentração nas áreas próximas a Serra da Jacobina, nas zonas próximas as planícies fluviais, nas praças que compõem o perímetro urbano, com predominância de plantas caducifólias 
xerófilas, principalmente as famílias Anacardiaceae; Vachellia, Senegalia, Mimosa, Chamaecrista, também da família Fabaceae. (IBGE, 2012).

Segundo a projeção do Instituto Brasileiro de Geografia e Estatística (IBGE, 2020), Senhor do Bonfim possui uma população de 74.419 habitantes, com predominância na área urbana da sede municipal, equivalente a $80 \%$ da população. Atualmente, o destaque econômico, além do setor comercial e de serviços, está na feira-livre, que por extensão é a maior da região e a segunda maior do Nordeste (IBGE, 2018). A área em estudo possui uma localização dentro do estado baiano que influenciou intrinsecamente o seu desenvolvimento socioeconômico por conectar a capital ao interior da Bahia, funcionando como entreposto comercial, importante aliado na histórica interiorização do Brasil (MACHADO, 1993).

\section{PROCEDIMENTOS METODOLÓGICOS}

Este trabalho foi dividido em três principais etapas; a primeira composta de revisão bibliográfica acerca da cartografia geomorfológica em ambientes semiáridos tropicais. A segunda, composta pela aquisição das fotografias aéreas e de satélites para definição dos pares estereoscópicos e realização da estereoscopia digital. A terceira etapa é caracterizada pelo georreferenciamento, vetorização, integração dos dados em ambiente de Sistema de Informação Geográfica (SIG) com uso do software QGIS (versão 3.10.8), e pela redação final da pesquisa. Apresentase a seguir, o detalhamento dos principais procedimentos relativos à segunda e à terceira etapa.

De início, foram adquiridas gratuitamente da Companhia Baiana de Pesquisa Mineral (CBPM, 2020) fotografias áreas em formato digital, em escala 1:70.000, datadas do ano de 1975. Em seguida, com base em Souza e Oliveira (2012), seguiuse a interpretação dos pares estereoscópicos utilizando o software StereoPhoto Maker versão 5.06 (SOUZA e OLIVEIRA, 2012). 
A interpretação dos pares estereoscópicos seguiu o método Anáglifo, que resulta da sobreposição de fotografias estereoscópicas em cores complementares (vermelho e azul), que observadas com o uso de óculos especiais de lentes coloridas proporciona a percepção de profundidade. As imagens tridimensionais obtidas a partir dos pares estereoscópicos foram salvas em formato [tiff]. para posterior utilização em ambiente SIG (SOUZA e OLIVEIRA, 2012).

Posteriormente a obtenção dos anáglifos digitais, realizou-se a construção de um mosaico com todas as imagens, seguida pelo georreferenciamento em escala 1:1.000, com base na cartográfica digital, elaborada pela Diretoria de Informações Geoambientais, disponibilizada gratuitamente pela Superintendência de Estudos Econômicos e Sociais da Bahia, no formato CD-ROM e em escala 1:100.000 (SEI, 2015).

Em sequência, iniciou-se a coleta das amostras através de polígonos, selecionando a opção "criar nova camada", criando um novo arquivo vetorial e adicionando feições. Por meio desse comando foi possível coletar feições referentes ao modelado disposto nas imagens anáglifas digitais. Ainda neste processo, utilizou-se imagens de satélite (Quadro 1) por meio do comando Bing Maps Aerial para auxiliar no reconhecimento das áreas, bem como dados da Carta Geológica e Topográfica de Senhor do Bonfim, em escala 1:100.000, disponibilizada pela CPRM (SEI, 2015). 
Quadro 1 - Classes amostrais dos compartimentos geomorfológicos.

\begin{tabular}{|c|c|c|c|}
\hline Compartimentos & $\begin{array}{c}\text { Imagem de } \\
\text { satélite }\end{array}$ & $\begin{array}{c}\text { Imagem } \\
\text { vetorizada }\end{array}$ & $\begin{array}{c}\text { Imagem em } \\
\text { campo }\end{array}$ \\
\hline Pedimento & & & . \\
\hline Planícies fluviais & & & \\
\hline Inselbergues & & & \\
\hline
\end{tabular}

Fonte: GOOGLE EARTH (2020); Fotos: autores (2019).

Posteriormente, seguiu-se a colocação de simbologias, por meio do 'compositor de impressão' e a realização de trabalho de campo, com o intuito de, sobretudo, aferir, atualizar e averiguar as informações mapeadas, assim como comparar e esclarecer algumas dúvidas sobre as informações obtidas na primeira etapa de gabinete. Desta forma, durante os trabalhos de campo foram realizadas atividades tais como: reconhecimento geral do campo, demarcação de pontos amostrais, descrição dos ambientes, observação e medição da altura das feições, identificação dos compartimentos geomorfológicos, dentre outras. Vale ressaltar que os pontos amostrais do campo foram registrados em uma ficha com base no Manual Técnico de Geomorfologia do IBGE (2009) .

É importante salientar que foi seguido o método do Manual Técnico de Geomorfologia do IBGE (2009) na definição do padrão cartográfico da estrutura mapeada, por meio dos compartimentos do relevo (IBGE, 2009). Para o padrão de 
cores seguiu-se a tabela indicada pelo Projeto RADAMBRASIL (ROSS, 1996; NUNES et al., 2006).

Nesse sentido, adaptaram-se os tipos de informação à área de pesquisa conforme a identificação da taxonomia do relevo, indicando as estruturas geomorfológicas, na zona urbana de Senhor do Bonfim, com base na taxonomia do Manual Técnico de Geomorfologia (IBGE, 2009) apresentada no Quadro 2 e tomando como referência os autores supracitados, o mapeamento realizado busca a compartimentação dos modelados e respectivas unidades geomorfológicas.

Quadro 2 - Categorias Geomorfológicas

\begin{tabular}{|c|c|c|}
\hline Categoria & Conceito & $\begin{array}{c}\text { Exemplo de representações } \\
\text { na área de estudo }\end{array}$ \\
\hline $\begin{array}{c}\text { Domínio } \\
\text { Morfoestrutural }\end{array}$ & $\begin{array}{l}\text { Ocorrem em escala regional e organizam os } \\
\text { fatos geomorfológicos segundo o arcabouço } \\
\text { geológico marcado pela natureza das rochas e } \\
\text { pela tectônica que atua sobre elas. }\end{array}$ & $\begin{array}{l}\text { A área em estudo está inclusa } \\
\text { no Domínio dos Cráton do } \\
\text { São Francisco, associada ao } \\
\text { Complexo Saúde, Complexo } \\
\text { Caraíba e Grupo Jacobina. }\end{array}$ \\
\hline $\begin{array}{c}\text { Regiões } \\
\text { Geomorfológicas }\end{array}$ & $\begin{array}{l}\text { Representam compartimentos inseridos nos } \\
\text { conjuntos litomorfoestruturais que, sob a ação } \\
\text { dos fatores climáticos pretéritos e atuais, lhes } \\
\text { conferem características genéticas comuns, } \\
\text { agrupando feições semelhantes, associadas às } \\
\text { formações superficiais e às fitofisionomias. }\end{array}$ & $\begin{array}{l}\text { A área de estudo está inserida } \\
\text { na Região Geomorfológica do } \\
\text { Piemonte da Diamantina }\end{array}$ \\
\hline $\begin{array}{c}\text { Unidades } \\
\text { Geomorfológicas }\end{array}$ & $\begin{array}{l}\text { Arranjo de formas altimétrica e } \\
\text { fisionomicamente semelhantes em seus } \\
\text { diversos tipos de modelados. }\end{array}$ & $\begin{array}{l}\text { Planícies Fluviais, Pedimentos, } \\
\text { Inselbergues }\end{array}$ \\
\hline Modelados & $\begin{array}{l}\text { Um polígono de modelado abrange um padrão } \\
\text { de formas de relevo que apresentam definição } \\
\text { geométrica similar em função de uma gênese } \\
\text { comum e dos processos morfogenéticos } \\
\text { atuantes, resultando na recorrência dos } \\
\text { materiais correlativos superficiais. }\end{array}$ & $\begin{array}{lr}\text { Os modelados } \\
\text { geomorfológicos da área } \\
\text { foram agrupados em dois } \\
\text { tipos: modelados de } \\
\text { acumulação e modelados de } \\
\text { aplainamento. }\end{array}$ \\
\hline
\end{tabular}

Fonte: Adaptado de IBGE (2009); RADAMBRASIL (1983). 
12 | Compartimentação geomorfológica da área urbana do município de Senhor do Bonfim - BA enquanto subsídio ao planejamento do uso e ocupação

\section{RESULTADOS E DISCUSSÕES}

Tendo em vista a escala regional adotada esta análise da compartimentação permitiu identificar na área urbana do município de Senhor do Bonfim - BA os compartimentos descritos na Tabela 1 e representados espacialmente na Figura 3.

Figura 3 - Compartimentação geomorfológica da área urbana de Senhor do Bonfim BA.

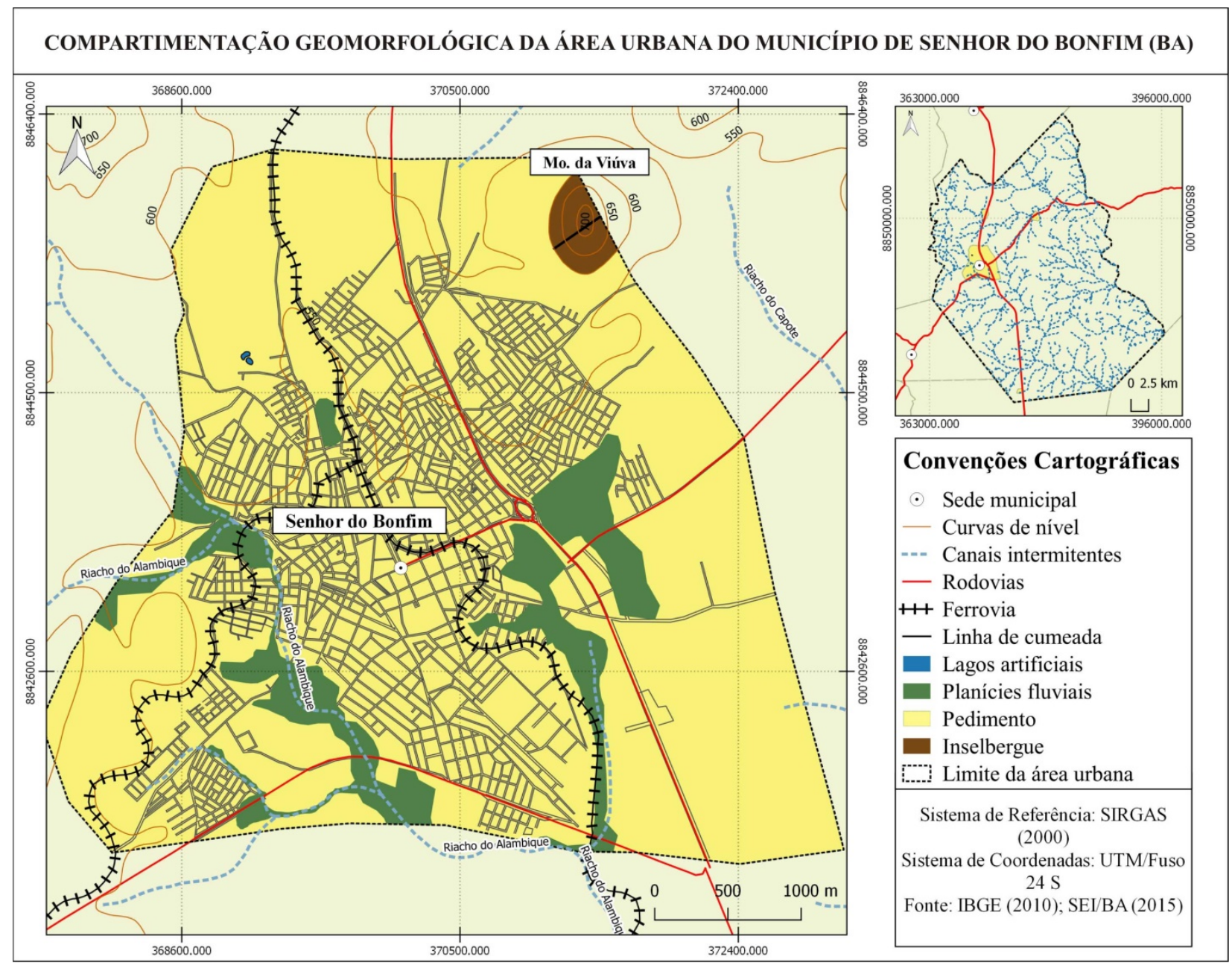

Fonte: Organização dos autores. (2020) 
Tabela 1 - Compartimentos geomorfológicos da área urbana de Senhor do Bonfim BA.

\begin{tabular}{lccc}
\hline \multicolumn{1}{c}{ Modelados } & Compartimentos & Área $\left(\mathbf{k m}^{2}\right)$ & Área (\%) \\
\hline Aplainamento & Pedimento & 20,42 & 91,1 \\
Acumulação & Planícies fluviais & 1,77 & 7,9 \\
Dissecação & Inselbergues & 0,20 & 1,0 \\
& & Total: 22,40 & 100,00 \\
\hline
\end{tabular}

Fonte: Organização dos autores. (2020)

Enquanto diagnóstico das feições, de acordo com a fotointerpretação descrita na metodologia, o modelado de aplainamento constitui-se o modelado predominante, cobrindo $20,429 \mathrm{~km}^{2}$, ou $91,1 \%$ da área urbana. Tal modelado representa a ocorrência de pedimentos, que para o IBGE (2009), são considerados enquanto superfície de aplainamento, de inclinação suave, capeada por material dendrítico.

Desta forma os pedimentos presentes na área de estudo são caracterizados pelo relevo plano, suave, pouco declivoso. Tais feições são resultantes da erosão no sopé das vertentes íngremes da Serra da Jacobina, que passaram por longos processos de deposição e aplainamento (BIGARELLA, MARQUES FILHO E AB'SABER, 1961).

$\mathrm{Na}$ área urbana de Senhor do Bonfim, o pedimento mapeado apresenta alta taxa de ocupação que, mediante a criação de novos conjuntos habitacionais, loteamentos e condomínios, principalmente ao norte e sul da área urbanizada, tende a manter crescente o nível de expansão. Foi possível observar, em campo, que neste compartimento predomina-se o uso urbano, ocupacional, pautado na expansão de condomínios e loteamentos. Entretanto, em alguns trechos nota-se também a existência de pequenos cultivos irrigados. Neste contexto de ocupação dos pedimentos, cabe ressaltar que apesar da permissão legal de uso e ocupação irrestrito, tais feições podem estar sujeitas a alagamentos e inundações periódicas, 
o que denota a necessidade de monitoramento e prevenção por parte dos gestores públicos (DENT e YOUNG, 1981; BRASIL, 2012).

Tais alagamentos e inundações relacionam-se a existência de chuvas torrenciais, muito frequentes em ambientes semiáridos tropicais (GUERRA SILVA e BOTELHO, 2005). Vale mencionar que o município já registrou alagamentos em diversos trechos da área urbana, onde se associam conjuntos habitacionais, deficiências no sistema de drenagem urbana, precárias condições de saneamento aliadas a impermeabilização do solo urbano, variáveis que resultam em extensos acúmulos pluviais.

Na sequência, o modelado de acumulação se configura pela presença de planícies fluviais, que recobrem um total de $1,77 \mathrm{~km}^{2}$ ou $7,9 \%$ da área urbana. Para o IBGE (2009), planícies fluviais correspondem a áreas planas, que resultam da combinação de processos de acumulação fluvial. Ainda pode-se afirmar que as planícies possuem larguras variadas e grande parte do seu percurso fluvial coincide com áreas de preservação permanente (APPs) dos rios (BRASIL, 2012).

$\mathrm{Na}$ área de estudo, as planícies fluviais bordejam a zona urbanizada e se associam diretamente aos canais efêmeros que drenam o município, como o Riacho do Alambique e o Canal da Malária. Neste âmbito, apesar de apresentarem baixo grau de ocupação, reitera-se a importância de que estas feições sejam preservadas e não ocupadas, tendo em vista que a presença de distintos processos hidromorfodinâmicos torna as planícies fluviais naturalmente instáveis, passíveis da ocorrência de enchentes e inundações periódicas.

Verificou-se, em campo, certo grau de preservação ambiental das planícies localizadas ao sul e oeste da área urbana. Já a leste, percebe-se sutil degradação e associação a zonas de descarte de resíduos sólidos, apesar de serem áreas de preservação obrigatória (Figura 4). Percebe-se que as maiores extensões de vegetação encontram-se ao sul, as margens do Riacho do Alambique (Figura 4). 
Figura 4 - Áreas de planícies fluviais na área urbana de Senhor do Bonfim - BA.

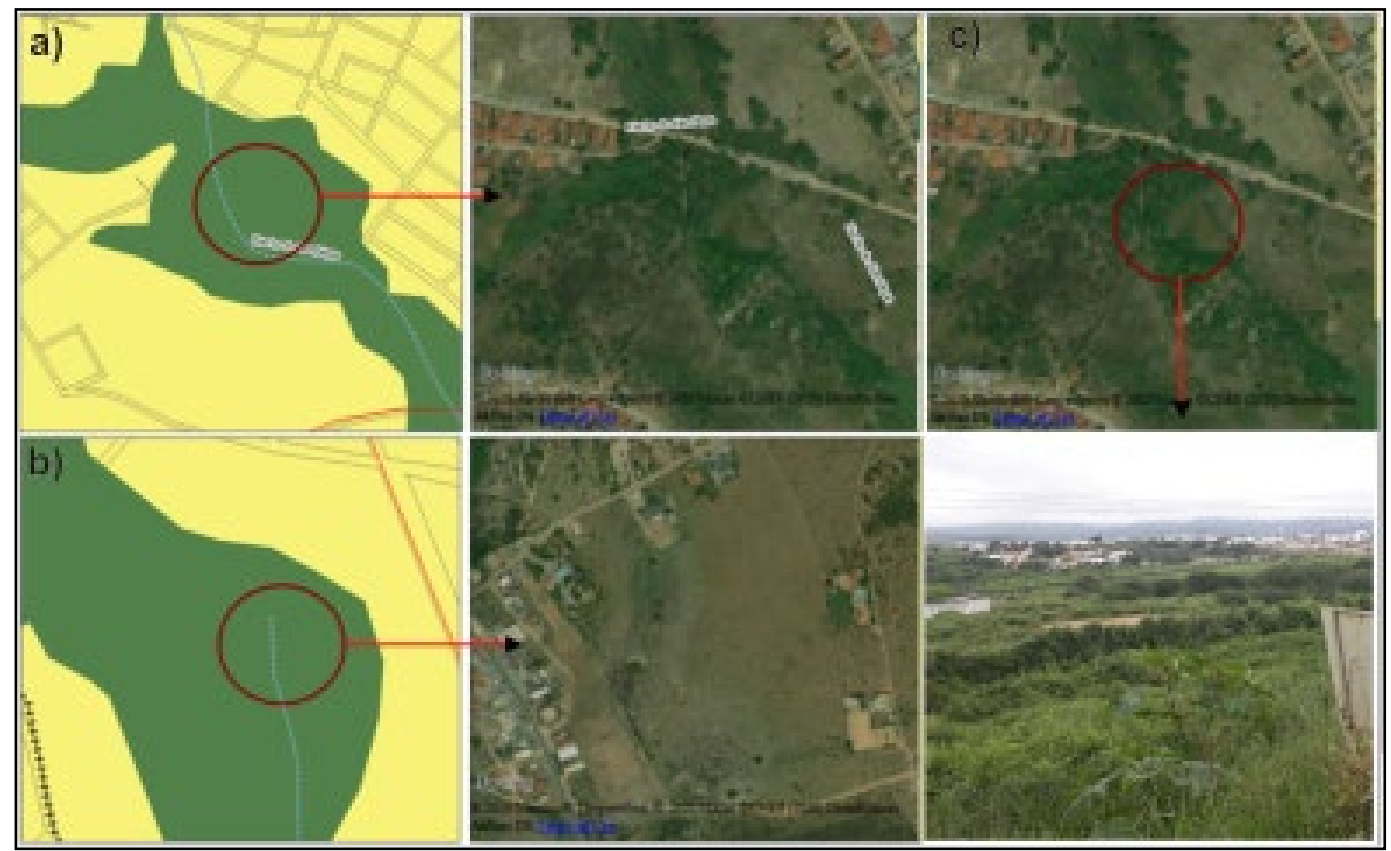

Fonte: Autores (2020); Google Earth (2020

Legenda: a) trecho ao sul da área urbana; b) trecho a leste da área urbana; c) Imagem de planícies fluviais próximas ao Riacho do Alambique, na região da área urbana.

Quanto ao modelado de dissecação identificado na área em estudo, a presença de um inselbergues compreende cerca de $0,203 \mathrm{~km}^{2}$, ou $1 \%$ do território urbano. Cabe ressaltar que ao longo município existem muitos outros inselbergues, contudo, na área urbana consta apenas um, ao norte. De modo geral, no município de Senhor do Bonfim, os inselbergues apresentam predominância de quartzitos, subordinadamente metaconglomerados, e seus depósitos de tálus são geralmente constituídos por fragmentos grossos e angulosos, localizados em seu sopé.

No inselbergue mapeado, foi possível perceber em campo certo grau de preservação da vegetação, que pode indicar menor desgaste nas vertentes amenizando possíveis eventos erosivos. Contudo, evidencia-se a presença de casas no topo do inselbergue denota risco aos moradores, em razão dos processos geomorfológicos relacionados a esta feição, como o fraturamento associado a expansão diferencial por alívio de pressão e a consequente ocorrência de deslocamento de blocos. 
Nesse sentido, reitera-se a necessidade de uma revisão destas ocupações e preservação destes ambientes, tendo como base a lei de parcelamento do solo urbano (BRASIL, 1979) que restringe a ocupação em áreas de elevada declividade, em razão do elevado nível de susceptibilidade a processos erosivos significativos. Logo, tais características podem apontar atributos que identificam possíveis zonas de risco na área urbana de Senhor de Bonfim, evidenciando a necessidade de preservação e desocupação destes locais, com o intuito da preservação da vida das pessoas e manutenção dos processos ambientais presentes.

\section{CONSIDERAÇÕES FINAIS}

Este trabalho foi norteado, essencialmente, pelo interesse em contribuir com o fortalecimento de análises geomorfológicas no semiárido baiano, partindo do pressuposto que o semiárido baiano carece de compartimentações geomorfológicas em escalas variadas. Desta forma, considera-se que o objetivo proposto foi atingido ao apresentarmos uma proposta de compartimentação geomorfológica para a área urbana de Senhor do Bonfim - BA, ao mesmo tempo em que considera-se que a metodologia adotada se mostrou eficaz.

Quanto aos resultados encontrados, identificou-se na área de estudo o predomínio do modelado de aplainamento, revelado na paisagem pela feição do pedimento. Tais pedimentos, são recobertos por intensa atividade de uso e ocupação, com destaque para o uso residencial e agrícola. Diante da sustentabilidade dos pedimentos, recomenda-se que as atividades de uso e ocupação sejam administradas devidamente levando-se em conta a distância (vertical e horizontal), entre a fonte poluidora e os canais fluviais superficiais e subterrâneos, indica-se também que o tipo de carga poluidora e competência de autodepuração sejam consideradas.

Para o modelado de acumulação identificado na área de estudo sob a forma de planícies fluviais, acrescenta-se que estas planícies são ocupadas 
prioritariamente enquanto áreas de descarte de resíduos sólidos e efluentes urbanos, com alguns pontos de cultivos agrícolas. Em razão da complexidade destas feições, recomenda-se que sejam criadas estratégias de conservação e preservação destes ambientes, com base na legislação ambiental vigente, visando a restauração e manutenção dos ecossistemas presentes. Ao passo que se recomenda também a implantação de um plano de gerenciamento de resíduos sólidos e tratamento de efluentes urbanos, evitando a contaminação das planícies em questão.

O modelado de dissecação aparece na área de estudo pela ocorrência de um inselbergue no limite nordeste da área urbana de Senhor do Bonfim (BA). Quanto a esta unidade, apesar da existência de algumas moradias, recomenda-se que o inselbergues seja conservado e que tenha o uso e ocupação restringido, em razão da possibilidade de fraturas e movimento de blocos, o que pode ocasionar danos as ocupações e construções já efetivadas.

De um modo geral, espera-se que este trabalho possa ser o ponto de partida para outros estudos e que forneça uma plataforma inicial para diferentes compartimentações geomorfológicas em ambientes semiáridos tropicais, que possam subsidiar formas de uso e ocupação compatíveis com as potencialidades e fragilidades do semiárido tropical brasileiro.

\section{AGRADECIMENTOS}

A Fundação de Amparo à Pesquisa do Estado da Bahia (FAPESB) pelo apoio e investimento ao longo do desenvolvimento da pesquisa, corroborando o estímulo à ciência, através do auxílio em todas as etapas deste projeto.

\section{REFERÊNCIAS}

AB'SABER, A. N. Um conceito de geomorfologia a serviço das pesquisas sobre o quaternário. Geomorfologia. São Paulo, no 18, p. 1-23, 1969. 
$A B$ 'SÁBER, A. N. Contribuição à geomorfologia da área dos cerrados. Universidade de São Paulo, 1963.

ACSELRAD, H. Cidadania e meio ambiente. Meio ambiente e democracia. Rio de Janeiro: IBASE, p. 18-31, 1992.

ADELI, Z.; KHORSHIDDOUST, A. Application of geomorphology in urban planning: Case study in landfill site selection. Procedia Social and Behavioral Sciences, vol. 19, p. 662-667, 2011.

BIERMAN, P.; MONTGOMERY, D. R. Key Concepts in Geomorphology. 2. ed. New York: W. H. Freeman and Company Publishers, 2013.

BIGARELLA, J. J., BECKER, R. D., PASSOS, E. Estrutura e Origem das Paisagens Tropicais e Subtropicais: 877-1436. Fundamentos geológico-geográficos, alteração química e física das rochas. Ed. da Univ. Federal de Santa Catarina, 1994.

BOCCO, G.; MENDOZA, M.; VELÁZQUEZ, A. Remote sensing and GIS-based regional geomorphological mapping-a tool for land use planning in developing countries. Geomorphology, v. 39, n. 3-4, p. 211-219, 2001.

BRASIL (1979). Dispõe sobre o Parcelamento do Solo Urbano e dá outras Providências. Disponível em: http://www.planalto.gov.br/ccivil_03/leis/L6766.htm. Acesso em: 11 out. 2011.

BRASIL (2012). Lei $\mathbf{n}^{\circ} \mathbf{1 2 . 6 0 8}$ de 10 de abril de 2012. Institui a Política Nacional de Proteção e Defesa Civil - PNPDEC; dispõe sobre o Sistema Nacional de Proteção e Defesa Civil - SINPDEC e o Conselho Nacional de Proteção e Defesa Civil - CONPDEC.

CARVALHO, C. S.; MACEDO, E.; OGURA, A. T. Mapeamento de riscos em encostas e margem de rios. Mapeamento de riscos em encostas e margem de rios. Brasília: Ministério das Cidades, 2007.

CASSETI, V. Cartografia Geomorfológica, 2005. Livro Digital. Disponível em: http://www.funape.org.br/geomorfologia/. Acesso em: 26 fev. 2020.

CHRISTOFOLETTI, A. Geomorfologia. São Paulo: Blucher, 1980.

COMPANHIA BAIANA DE PESQUISA MINERAL - CBPM. Bacia do São Francisco entre Santa Maria da Vitória e Iuiú, Bahia: geologia e potencialidade econômica Salvador, 2020. Disponível em: http://www.cbpm.ba.gov.br/. Acesso em: 05 nov. 2018.

COMPANHIA BAIANA DE PESQUISA MINERAL - CBPM. geologia e potencialidade econômica. Valter Mônaco Conceição Filho; Marcos Donadello Moreira. Série Arquivos Abertos, v. 15, 2003. 
COMPANHIA DE PESQUISAS DE RECURSOS MINERAIS - CPRM. - Curitiba - Folha SG.22-X-D-I Estado do Paraná. Programa levantamentos geológicos básicos do Brasil. São Paulo, DNPM ICPRM Min. Minas e Energia, 2019. Disponível em: http://www.sei.ba.gov.br/site/geoambientais/mapas. Acesso em: 19 jun. 2020.

CUNHA, C. L. et al. A Cartografia do Relevo: Uma Análise Comparativa de Técnicas para a Gestão Ambiental. Revista Brasileira de Geomorfologia. Ano 4, nº1, p. 1 - 9, 2003.

DENT, D. et al. Soil survey and land evaluation. George Allen \& Unwin., 1981.

DOS SANTOS, H. G. et al. Sistema brasileiro de classificação de solos. Brasília, DF: Embrapa, 2018., 2018.

EISANK, C. Geomorphology Object representations at multiple scales from digital elevation models. v. 129, p. 183-189, 2011.

EMPRESA BRASILEIRA DE PESQUISA AGROPECUÁRIA - Embrapa. Sistema brasileiro de classificação de solos. Centro Nacional de Pesquisa de Solos: Rio de Janeiro, 2013.

GUERRA, A.J.T.; SILVA, A.S.; \& BOTELHO, R.G.M. (Org). Erosão e Conservação dos Solos: conceitos, temas e aplicações. $2^{\text {a }}$ Ed. Rio de Janeiro. Bertrand Brasil. 2005.

INMET. Instituto Nacional de Meteorologia, Ministério da Agricultura, Pecuária e Abastecimento, 2019. Disponóvel em: http://wwww.inmet.gov.br/portal/. Acesso em: 25 fev. 2020.

INSTITUTO BRASILEIRO DE GEOGRAFIA E ESTATÍSTICA - IBGE. Censo Demográfico 2010. Rio de Janeiro: IBGE, 2018.

INSTITUTO BRASILEIRO DE GEOGRAFIA E ESTATÍSTICA - IBGE. Censo Demográfico 2010. Rio de Janeiro: IBGE, 2020.

INSTITUTO BRASILEIRO DE GEOGRAFIA E ESTATÍSTICA - IBGE. Coordenação de Recursos Naturais e Estudos Ambientais. Manual técnico de geomorfologia. $2^{\mathrm{a}}$ ed. Rio de Janeiro, RJ, 2009.

INSTITUTO BRASILEIRO DE GEOGRAFIA E ESTATÍSTICA - IBGE. Manual técnico da vegetação brasileira. Manuais técnicos em geociências, v. 1, 2012.

JATOBÁ, L.. A Geomorfologia do Semiárido. Universidade Federal de Pernambuco, 1994.

LEOPOLD, L. B.; MILLER, J. P. Ephemeral Streams: Hydraulic Factors and Their Relation to Drainage Net. Professional Paper 282-A. Washington: U.S. Geological Survey, 1956.

LIMA, K. C.; CUNHA, C. M. I. atualização cartográfica da rede de drenagem para estudo geomorfológico de rios intermitentes e efêmeros do semiárido. Revista Brasileira de Cartografia, v. 66, n. 1, 2014. 
LIMBERGER, L. Abordagem sistêmica e complexidade na geografia. Geografia, v. 15, n. 2, p. 95-109, 2006.

MACHADO, P. B.. Cartilha Histórica sobre as origens de Senhor do Bonfim. Salvador: Universidade do Estado da Bahia, 1993.

MENDES, B. C. Mapeamento geomorfológico aplicado ao estudo do uso e cobertura da terra no Planalto Central. . vii, 74 f., il. Dissertação (Mestrado em Geociências Aplicadas) 2015.

NUNES, J. O. R; FREIRE, R; PEREZ, I. . Mapeamento geomorfológico do perímetro urbano de Presidente Prudente-SP. In: Simpósio Nacional de Geomorfologia e Regional Conference on Geomorphology. 2006.

QUEIROZ, D.S. A Cartografia Geomorfológica de Detalhe: Uma Proposta visando a Multidisciplinaridade. REVISTA CLIMEP. Rio Claro, vol. 7, n. 1-2, p. 22, 2012.

RADAMBRASIL. Levantamento de Recursos Naturais - Folha SC.24/25 Aracaju/Recife; Geologia, Geomorfologia, Pedologia, Vegetação, Uso potencial da Terra. Edição Facsimilar. Volume 34, Rio de Janeiro: IBGE, 1983.

ROSS, J. L. S. O registro cartográfico dos fatos geomorfológicos e a questão da taxonomia do relevo. Revista Do Departamento De Geografia, v. 6, p. 17-29, 1992.

ROSS, J. L. S; MOROZ, I. C. Mapa geomorfológico do estado de São Paulo. Revista do Departamento de Geografia, v. 10, p. 41-58, 1996.

SAADI, A. A Geomorfologia como ciência de apoio ao planejamento urbano em Minas Gerais. Geonomos, 1997.

SANTOS, C. A.; SOBREIRA, F. G.; SILVA, S. P. Cartografia geomorfológica como subsídio ao ordenamento territorial das bacias do ribeirão Carioca, córrego do Bação e córrego Carioca, Itabirito, MG. $6^{\circ}$ SIMPÓSIO NACIONAL DE GEOMORFOLOGIA. GOIÂNIA-GO. UGB. CD Anais, 2006.

SANTOS, J. P. A. dos et al. Mapeamento geomorfológico e análise do uso e cobertura da terra em áreas do maciço de Água Branca e seu entorno. 2020.

SMITH, M.J.; PARON, P.; GRIFFITHS, J.S. Geomorphological mapping: methods and applications. Elsevier; Amsterdam, 2011, 2 ed. 612 p.

SOUZA, T. A.; OLIVEIRA, R. C. Avaliação Da Potencialidade De Imagens Tridimensionais Em Meio Digital Para O Mapeamento Geomorfológico. REVISTA GEONORTE, Edição Especial, V.2, N.4, p.1348 - 1355, 2012.

SUPERINTENDÊNCIA DE ESTUDOS ECONÔMICOS E SOCIAIS DA BAHIA. Perfil dos Territórios de Identidade. (Série territórios de identidade da Bahia, v. 3). Salvador: SEl, 2018. 
SUPERINTENDÊNCIA DE ESTUDOS ECONÔMICOS E SOCIAIS DA BAHIA. Perfil dos Territórios de Identidade. (Série territórios de identidade da Bahia, v. 1). Salvador: SEl, 2015

VASCONCELOS, T. L. et al., Estudo Morfodinâmico Em Área Do Semi-Árido Do Nordeste Brasileiro: Um Mapeamento Geomorfológico Em Micro Escala. Revista de Geografia (Recife), v. 24 , n. 2, p. 36-49, 2008.

\section{1 - Felipe Souza Reis:}

Bolsista de Iniciação Científica da Fundação de Amparo à Pesquisa do Estado da Bahia no Curso de Licenciatura em Geografia da UNIVASF - campus Senhor do Bonfim, https://orcid.org/0000-0003-3650-350X•felipe.reis@discente.univasf.edu.br Contribuição: Concepção, coleta de dados, elaboração do mapeamento e redação da pesquisa.

\section{2 - Sirius Oliveira Souza:}

Professor Adjunto do Colegiado de Geografia da Universidade Federal do Vale do São Francisco - Campus Senhor do Bonfim. Doutor em Geografia pela Universidade Estadual de Campinas - UNICAMP, https://orcid.org/0000-0001-8831-5709•sirius.souza@univasf.edu.br Contribuição: Concepção, coleta de dados, supervisão do mapeamento e da redação da pesquisa.

\section{Como citar este artigo}

REIS, F. S.; SOUZA, S. O. Compartimentação geomorfológica da área urbana do município de Senhor do Bonfim - BA enquanto subsídio ao planejamento do uso e ocupação. Geografia Ensino \& Pesquisa, Santa Maria, v. 25, e35, p. 1-21, 2021. DOI 10.5902/2236499463075. Disponível em: https://doi.org/10.5902/2236499463075. Acesso em: dia mês abreviado. ano. 